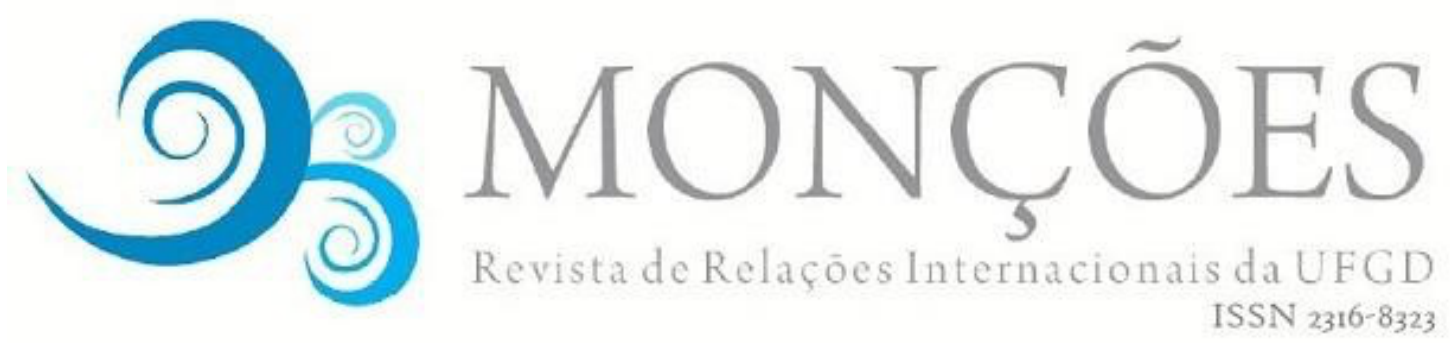

\title{
MULHERES NEGRAS NAS UNIVERSIDADES E SABERES DECOLONIAIS: POR UMA TEORIZAÇÃO DE UM PENSAMENTO FEMINISTA NEGRO
}

\author{
LUCIANA DE OLIVEIRA DIAS \\ Universidade Federal de Goiás (UFG) Professora Associada da Faculdade de \\ Ciências Sociais, Goiânia, Goiás, Brasil. \\ ORCID: https://orcid.org/0000-0002-2570-8078 \\ lucianadias@ufg.br
}

\begin{abstract}
ANA LUÍSA MACHADO DE CASTRO
Universidade Federal de Minas Gerais (UFMG), Doutoranda do Programa de Pósgraduação em Ciência Política (DCP-UFMG), Belo Horizonte, Minas Gerais, Brasil.

ORCID: https://orcid.org/0000-0002-1237-2288 analuisamachadodecastro@gmail.com
\end{abstract}

Resumo: No Brasil deste século XXI, as universidades têm experimentado novos itinerários e delineado novas trajetórias que foram provocadas, sobremaneira, pela adoção de políticas de ações afirmativas em seus processos de ingresso e permanência, em vários níveis. Além de mudanças na composição étnico-racial das universidades, pode ser notada especificamente uma maior presença de mulheres negras nesses espaços. Essas presenças, associadas à afirmação de um Pensamento Feminista Negro, têm desestabilizado modelos instituídos e normativos: tanto no âmbito das interações sociais que são sedimentadas em estruturas nas quais as mulheres negras ocupam a sua base; quanto no campo da produção de conhecimentos, e de disputas teóricas, campo este que é forçado a não mais lidar com mulheres negras meramente como objetos de pesquisa, mas na condição de produtoras, e estudiosas, de saberes que têm revelado dimensões decoloniais. A partir desses pressupostos, discutimos neste artigo, em uma perspectiva interdisciplinar, em que medida essas movimentações, que tornaram os espaços mais plurais, implicam em uma emergência de novos pensamentos e saberes e também em uma realização de dignidades, tais quais aquelas previstas nos Direitos Humanos, que foram historicamente perdidas.

Palavras Chaves: Mulheres Negras; Saberes Decoloniais; Pensamento Feminista Negro; Direitos Humanos.

\section{BLACK WOMEN IN UNIVERSITIES AND DECOLONIAL KNOWLEDGE: FOR A THEORIZATION OF A BLACK FEMINIST THOUGHT}

Abstract: Over the 21st century, Brazilian universities have been going through new and major changes, at different levels, as a result of the adoption of affirmative actions in their processes of admissions and permanence. Besides changes in the racial and ethnic profile of students, there is also an increasing presence of black women at Brazilian universities, which is ultimately related to the reinforcement of the black feminist thought. This increasing presence of black women is challenging previously adopted models, not only within the framework of social interactions that are now based on structures where black women occupy a leading role but also in the field of science and its different theoretical perspectives. More than ever, the research field is being required not to treat black women as mere objects, but rather as 
researchers and scholars that are responsible for shedding light on a new type of knowledge, with decolonial dimensions. In view of this, the main objective of this paper is to discuss, from an interdisciplinary perspective, to what extent these new changes, which contributed to improving diversity in universities, imply an emergence of new thoughts and knowledge, as well as the achievement of dignity and human rights, which was historically lost.

Keywords: Black Women; Decolonial Knowledge; Black Feminist Thinking; Human Rights.

\section{MUJERES NEGRAS EN UNIVERSIDADES Y CONOCIMIENTO DECOLONIAL: POR LA TEORIZACIÓN DE UN PENSAMIENTO FEMINISTA NEGRO}

Resumen: En Brasil en este siglo XXI, las universidades están experimentando nuevos itinerarios y trazando nuevas trayectorias. Esta novedad se debió, principalmente, a la adopción de políticas de acción afirmativa en sus procesos de ingreso y permanencia, en los distintos niveles educativos. Además de los cambios en la composición étnico-racial de las universidades, se puede notar específicamente una mayor presencia de mujeres negras en estos espacios. Estas presencias, asociadas a la afirmación de un Pensamiento Feminista Negro, han desestabilizado modelos establecidos y normativos: tanto en el contexto de interacciones sociales que se basan en estructuras en las que las mujeres negras ocupan su base; como en el campo de la producción de conocimiento y de las disputas teóricas, este campo se ve obligado a no tratar más a las mujeres negras como meramente objetos de investigación, sino como productoras de conocimientos que han revelado dimensiones decoloniales. A partir de estos supuestos, discutimos en este artículo, en una perspectiva interdisciplinar, hasta qué punto estos movimientos, que hicieron espacios más plurales, implican la emergencia de nuevos pensamientos y conocimientos y también en la realización de dignidades, como las previstas en los Derechos Humanos. Estos que se han perdido históricamente.

Palabras clave: Mujeres Negras; Conocimiento decolonial; Pensamiento Feminista Negro; Derechos humanos.

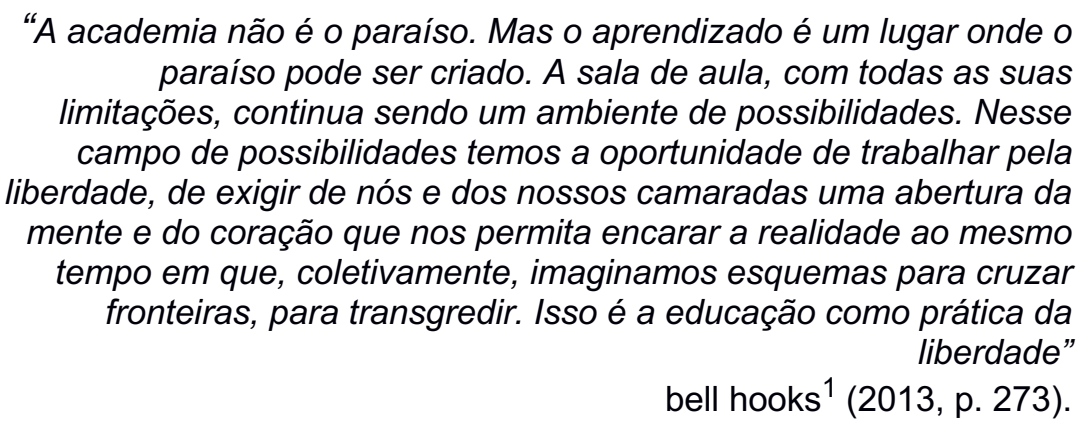

\section{Apresentação}

Nos últimos anos, a adoção de políticas de ações afirmativas e afroreparatórias nas universidades públicas brasileiras têm provocado mudanças na composição racial desses espaços. Pode ser percebido um aumento da inserção de

\footnotetext{
1 Pseudônimo (escrito em minúsculas por uma opção política da própria bell hooks) da escritora, educadora, feminista e ativista social estadunidense Gloria Jean Watkins.
} 
mulheres negras nas universidades e no campo de produção e reprodução do conhecimento, de teorizações, sendo que as mesmas têm passado a ser vistas não mais como meros objetos de pesquisa, mas como sujeitos que possuem e produzem conhecimentos (GOMES, 2010). Com base nessa perspectiva, realizamos reflexões sobre saberes decoloniais como uma possibilidade de efetivação de direitos humanos nas universidades brasileiras, na contemporaneidade, a partir de algumas reflexões acerca das presenças de mulheres negras nas universidades brasileiras e da consolidação de um Pensamento Feminista Negro.

Para introduzir a temática proposta foram discutidos alguns processos de produção de conhecimentos nas universidades, estas que são responsáveis por $90 \%$ do conhecimento científico produzido no Brasil (ANDIFES, 2016). Partirmos da concepção de que o saber/fazer que é tomado como conhecimento científico foi herdado de uma modernidade que se conjuga com uma colonialidade. Entendemos que a colonização que oprimiu povos não europeus tanto economicamente, quanto na dimensão religiosa, política e laboral, o fez também na dimensão epistêmica. Os genocídios foram combinados com epistemicídios e foi também sobre esses dispositivos, consolidadores das hierarquias raciais (CARNEIRO, 2005), que as universidades se estabeleceram.

Desde o início dos anos 2000, as universidades brasileiras têm adotado políticas de ações afirmativas, ou políticas afro-reparatórias, que têm colaborado para promover mudanças profundas que são merecedoras de reflexões. Destacamos duas impactantes mudanças alcançadas neste século XXI: a primeira diz respeito a uma alteração estética, que está relacionada a uma maior presença de pessoas negras, na condição de estudantes. De acordo com levantamento realizado pela Universidade de Brasília (UnB), as presenças negras nas universidades "triplicaram em dez anos" (CARDIM; CARAMORI, 2019) e, desta forma, não há como negar a ativação de processos de ressignificação dos corpos, não mais tão homogêneos racialmente, que passaram a compor o quadro discente. A segunda diz sobre uma alteração ética já que com a introdução de corpos marcados racialmente faz-se presente também dimensões alicerçadas em outras cosmologias, outras culturas, outras linguagens, outros valores e outras formas de saber e fazer. O que se tem notado são fissuras provocadas em estruturas erigidas e que foram sustentadas por uma base ética e 
estética particular e localizada, tornada universal, provocando uma espécie de giro decolonial (CASTRO-GOMEZ; GROSFOGUEL, 2007), merecedor de mais atenção.

A atenção a esse movimento permite observar que representações sociais estereotipadas das mulheres negras vigoram e são responsáveis pela constatação que inferioriza e pela projeção que colabora com a construção de novos sujeitos eficazmente emoldurados a uma perspectiva estigmatizante. Essa prevalência alimenta-se da herança colonial do racismo, bem como da herança patriarcal do machismo, que aprisiona as mulheres negras em uma teia de múltiplos preconceitos e discriminações que se interseccionam. O imaginário coletivo prevalecente conta com a eficácia das representações sociais estereotipadas que tem dificultado uma apreensão coletiva das mulheres negras como intelectuais e produtoras de saberes.

O feminismo negro "amefricano" (GONZALEZ, 2018), presente inclusive no âmbito das universidades, tem colaborado para um desmantelamento desse imaginário coletivo e tem contribuído para que sejam delineados outros horizontes indicadores de outras possibilidades de existência, não mais reprodutoras dos saberes hegemônicos, mas reveladoras de potencialidades e humanidades que foram histórica, social e politicamente violentadas. As pautas pontuadas pelo feminismo negro brasileiro contemporâneo pressupõem posturas antirracistas e anti-machistas que considerem as "escrevivências" (SOARES; MACHADO, 2017), como escritas que nascem de um cotidiano engajado e militante, inclusive no âmbito das universidades e dos esforços de teorização que ali são exercitados. O que, por sua vez, dialoga diretamente com propostas de uma educação em/para Direitos Humanos, sendo esta proposta uma potente aliada na ativação de processos de transformação sociocultural e de realização de equidade e justiça social.

\section{Processos de (re)produção de conhecimentos nas universidades}

O contexto de modernidade e organização colonial do mundo, que é concomitante aos processos de colonização das Américas, fez com que imaginários, saberes, linguagens e memórias fossem constituídos também de acordo com as máximas eurocêntricas da colonização. A expansão colonial acontecida durante o século $X V$, além impor um padrão hegemônico de dominação às dimensões econômica e religiosa, atribuiu formas "hegemônicas de conhecimento, impondo-se como hegemonia epistêmica, política e historiográfica, estabelecendo, assim, a 
colonialidade do saber" (OLIVEIRA; CANDAU, 2010, p. 21). Neste sentido, a modernidade e a organização colonial do mundo influenciaram diretamente no conhecimento produzido e reproduzido no interior das universidades. Herdeira desses processos, a universidade brasileira se consolidou como uma instituição que é produto e produtora de um modelo, pretensamente universal, de gerar e gerir conhecimentos.

As universidades no Brasil deslizam, em muitos casos, ainda hoje, sobre a mesma esteira da ciência moderna e do racionalismo de René Descartes (1596-1650) que consolidou o conhecimento científico moderno. E, nesse movimento de consolidação, múltiplos saberes foram lançados para uma margem, quando não foram aniquilados, do campo do conhecimento científico, delineando uma universidade ocidentalizada (GROSFOGUEL, 2016). Sobre a estrutura de conhecimentos erigida nas universidades ocidentalizadas, Ramón Grosfoguel (2016) apresenta um questionamento que merece realce aqui: como foi possível que grande parte do pensamento das ciências sociais e das humanidades se baseasse na produção de poucos europeus? E, como esses europeus teriam alcançado tal privilégio epistêmico a ponto de suas ideias serem consideradas superiores às ideias oriundas do resto do mundo? Em uma busca por respostas a esses questionamentos, o autor aponta para quatro genocídios/epistemicídios constitutivos dessa estrutura de conhecimento ocidentalizada que influenciam ainda hoje a produção e reprodução de conhecimentos nas universidades. Quais sejam:

1. contra os muçulmanos e judeus na conquista de Al-Andalus em nome da 'pureza do sangue'; 2. contra os povos indígenas do continente americano, primeiro, e, depois, contra os aborígenes na Ásia; 3. contra africanos aprisionados em seu território e, posteriormente, escravizados no continente americano; e 4. contra as mulheres que praticavam e transmitiam o conhecimento indo-europeu na Europa, que foram queimadas vivas sob a acusação de serem bruxas. (GROSFOGUEL, 2016, p. 31).

A partir dessa compreensão, elucida-se o entendimento de que as universidades ocidentalizadas internalizaram estruturas compostas por pilares xenofóbicos, etnocêntricos, racistas e sexistas que privilegiam o conhecimento europeu, branco e masculino, e que desconsideram outras epistemologias, outras cosmologias e outras formas de saberes e fazeres. Ângela Figueiredo e Ramón Grosfoguel (2009, p. 223) enfatizam que "a perspectiva particular do homem branco se ergue como a norma universal de produção de conhecimentos, por meio da qual 
se medem e avaliam todas as outras formas de produzir conhecimentos". Especificamente acerca da condição moderna e colonial das universidades, Tchella Fernandes Maso e Leila Yatim (2014, p. 34) assinalam que

\begin{abstract}
Dividida em faculdades, departamentos, disciplinas e especialidades, essa instituição legitima hierarquias e constrói fronteiras epistêmicas inaptas ao diálogo de saberes. No mesmo sentido, ao legitimar o conteúdo científico, construído com rigor metódico - na maioria das vezes com cunho positivista, empiricista e naturalista -, silencia-se sobre outras cosmovisões.
\end{abstract}

Além dessa silenciadora fragmentação, as universidades ocidentalizadas, em uma busca desenfreada pela neutralidade científica, promoveram a separação entre o sujeito que conhece e o objeto a ser conhecido. Acerca da neutralidade científica, Ramón Grosfoguel (2016, p. 30) enuncia uma "egopolítica do conhecimento" reveladora de um "Eu" não localizado e sem referenciais que o situaria em um ponto específico, um sujeito que acredita na possibilidade inquestionável de produzir conhecimento a partir de "um não lugar". As universidades ainda incorporam essa defesa da neutralidade para classificar o que é cientifico, autorizar sujeitos produtores de conhecimento e legitimar temáticas a serem pesquisadas. Todavia, contemporaneamente, há resistências e dissidências a esses modelos e afirmação de outras existências nos campos de produção e reprodução de conhecimentos nas universidades.

Tanto a neutralidade, quanto a universalização de um conhecimento ocidental, têm sido questionadas, contemporaneamente. A consciência desse percurso caracterizado pela modernidade e colonialidade, operando inclusive nos campos de produção do conhecimento, faz com que desponte uma perspectiva decolonial ciente dos processos de opressão de base colonial e atenta à pluralidade de saberes e fazeres, na qual o conhecimento ocidentalizado é somente uma possibilidade dentre tantas outras, tão coerentes, sofisticadas e eficazes quanto. Ainda que não fale a partir da decolonialidade, Patricia Hill Collins (2016, p. 101), precursora do Pensamento Feminista Negro, aponta que "é impossível separar a estrutura e o conteúdo temático de pensamentos das condições materiais e históricas que moldam as vidas de suas produtoras". Assim sendo, é um equívoco, e uma impossibilidade empírica, a separação entre uma localização étnica, racial, de classe, sexual e de gênero daquele sujeito que enuncia e o conteúdo produzido por esse mesmo sujeito. Neste mesmo 
sentido, Nilma Lino Gomes (2010, p. 419) adverte que "toda investigação científica é contextualmente localizada e subjetivamente produzida".

Ainda que esta seja uma compreensão relativamente generalizada, não são raras as situações nas quais pesquisadores e pesquisadoras têm seus trabalhos questionados e temáticas tratadas com desconfiança e, muitas vezes, são desqualificadas e deslegitimadas sob a acusação de estarem próximas demais do seus "objetos" de pesquisa. Ângela Figueiredo e Ramón Grosfoguel (2009) discutem essa tensão experimentada sobretudo por pessoas negras que desenvolvem pesquisas nas universidades, cuja temática central são as relações raciais. Já a pensadora negra Sueli Carneiro (2005) estuda o "dualismo racial" objetivando compreender como uma geração de intelectuais negros e negras têm rompido barreiras que estruturam uma tradição acadêmica hegemônica e hierarquizam sujeitos produtores do conhecimento e temáticas abordadas em campos específicos. Há um campo onde o epistemicídio se manifesta, qual seja:

[...] no dualismo do discurso militante versus discurso acadêmico, através do qual o pensamento do ativismo negro é desqualificado como fonte de autoridade do saber sobre o negro, enquanto é legitimado o discurso do branco sobre o negro. Via de regra a produção branca e hegemônica sobre as relações raciais dialoga entre si, deslegitimando a produção dos pesquisadores e ativistas negros sobre o tema. Isso é claramente manifesto nas listas bibliográficas utilizadas onde, via de regra, figuram autores negros não-brasileiros, ou no fato de quão poucos intelectuais negros brasileiros alcançaram prestígio nacional e internacional. Os ativistas negros, por sua vez, com honrosas exceções, são tratados, pelos especialistas da questão racial, como fontes de saber, mas não de autoridade sobre o tema. (CARNEIRO, 2005, p. 60).

Partindo do pressuposto de que não há como se desvencilhar de uma localização, ou pertencimento, do sujeito que pesquisa de sua atuação como sujeito pesquisador, identificamos, a partir da descrição acima, uma tensão vivenciada especificamente por pesquisadores negros e pesquisadoras negras. Para melhor visualizar essa tensão presente nas universidades, que são espaços por excelência de produção de conhecimentos, e reconhecendo a relevância da posicionalidade na produção do conhecimento, recorremos a alguns dados que ajudam a evidenciar a composição racial nas universidades brasileiras. José Jorge de Carvalho e Rita Laura Segato apontam (apud DIAS, 2012) que, em 2001, apenas 1\% dos discentes da UnB eram negros, cenário que se repetia na maioria das universidades federais do país. $A$ 
Pesquisa Nacional por Amostra de Domicílio de 2006, do Instituto Brasileiro de Geografia e Estatística (IBGE), aponta que aproximadamente $30 \%$ dos estudantes no ensino superior se autodeclaravam pretos ou pardos.

Uma pesquisa apresentada em 2016 pela Associação Nacional dos Dirigentes das Instituições Federais de Ensino Superior (Andifes) demonstrou que políticas de expansão e inclusão foram responsáveis por mudanças profundas no perfil dos estudantes das Instituições de Ensino Superior. No quesito cor/raça, o relatório evidencia o impacto da adoção de ações afirmativas nas universidades federais. A Andifes (2016) demonstra que, em números absolutos, entre os anos de 2003 a 2014, os estudantes brancos eram em torno de 278 mil nas universidades, hoje são 429 mil. Os estudantes autodeclarados pardos eram 132 mil e, atualmente, são 354 mil. Já os estudantes pretos que eram 27 mil, hoje são 92 mil, o que representa que o número de estudantes negros (pretos + pardos) nas universidades brasileiras triplicou, no período estudado. Quanto a dados que informem sobre racismo e machismo operando na exclusão de mulheres negras das universidades, denunciamos aqui sua quase inexistência. Ainda assim, registramos que a pesquisa Gênero e Número (FERREIRA, 2018) informou que, entre o corpo docente atuante na pós-graduação em todo o Brasil, menos de 3\% é de doutoras negras. Em todo o estado de Goiás que conta com centenas de programas de pós-graduação em suas universidades federal e estadual e também nos Institutos Federais - a pesquisa da Gênero e Número revelou que somente seis doutoras pretas são docentes na pós-graduação em Goiás.

Uma questão provocada por esse contexto gravita em torno da tentativa de compreender em que medida uma cultura acadêmica tem mudado suas práticas, com o aumento dessas presenças discentes negras nas universidades. Reafirmamos a ideia de que as ações afirmativas nas universidades brasileiras, especificamente as políticas afro-reparatórias, têm sido essenciais para modificar um quadro de ausências e invisibilidades de pessoas negras. O desdobramento desta questão é: em que medida tem sido alterado tanto o perfil racial de estudantes e docentes quanto os conhecimentos produzidos nessas instituições? E, essas mudanças têm indicado uma abertura para uma perspectiva decolonial?

A experiência da Universidade Federal de Goiás (UFG) nos ajuda a esboçar respostas ou pelo menos aprofundar em algumas reflexões acerca desses questionamentos. A UFG adota, desde o ano de 2008, ações afirmativas para 
pessoas negras e indígenas, sendo que a institucionalização do programa ocorreu com a implantação UFGInclui, que antecipou a política nacional de reserva de vagas definida na Lei $12.711 / 2012$. A maior presença de estudantes negros e negras nos cursos de graduação indicou uma alteração no perfil racial do corpo discente e também fez com que uma demanda por ações afirmativas na pós-graduação emergisse. Em resposta a essa demanda e a partir da articulação de alguns docentes atuantes nos programas de pós-graduação em Antropologia Social e Direitos Humanos, o CONSUNI - Conselho Universitário da UFG aprovou, de maneira pioneira, no dia 24 de abril de 2015, a resolução para estabelecimento de cotas raciais e ações afirmativas para todos os programas de pós-graduação stricto sensu da instituição.

Resultado de uma investida individual atenta a essas mudanças, sugerimos que seja desenvolvido um estudo criterioso para verificar os impactos que as ações afirmativas tem promovido no campo da produção, reprodução e difusão dos conhecimentos nas universidades brasileiras. Por ora, evidenciamos o trabalho desenvolvido pelas pesquisadoras Lilian M. Grisolio e Luciana Dias (2017) que demonstrou que com a implementação das Leis 10.639/03 e 11.645/08 responsáveis pela alteração da Lei de Diretrizes e Bases da Educação Nacional (LDB 9394/96), instituindo a obrigatoriedade do ensino de história e cultura africana, afrobrasileira e indígena - a educação tem se convertido em espaço de produção, reprodução e difusão de conhecimentos mais decoloniais, interculturais, antirracistas, antimachistas e democráticos.

Enfim, essas mudanças - tanto em termos quantitativos, que são evidenciados pela maior presença de pessoas negras nas universidades, quanto em termos qualitativos, que são evidenciados por uma produção intelectual que prestigia uma diversidade cosmológica e epistemológica antes desconsiderada e agora acionada por intelectuais e pesquisadores negros e, também, indígenas e quilombolas - têm indicado uma abertura para uma perspectiva decolonial. Há um movimento de reestruturação de bases epistêmicas por meio da aquisição de uma consciência da multiplicidade de saberes, da pluralidade de existências e, consequentemente, da diversidade de necessidades expressas. No âmbito da UFG, a graduação em Educação Intercultural Indígena oferece há quase uma década e meia a licenciatura para indígenas aldeados que inserem cosmologias e demandas sustentadas em três 
eixos básicos, quais sejam a interculturalidade, a transdisciplinaridade e a decolonialidade (DIAS, 2020). Destacamos também os diversos grupos e núcleos de pesquisa que se formaram na última década como, por exemplo, o Coletivo Rosa Parks, um grupo que conta com mais de cinquenta pesquisadoras, negras em sua maioria, que estudam o Pensamento Feminista Negro no âmbito das graduações e pós-graduações, desde uma perspectiva interdisciplinar, interseccional e decolonial.

\section{Presenças de intelectuais negras versus imaginário coletivo estereotipado}

De acordo com bell hooks (1995), o trabalho intelectual, em muitos momentos, aproxima o sujeito do sofrimento e da dor pois o desperta para duras realidades, como a noção de que empreendimentos de dominação e de opressão moldam a vida de todas as pessoas, especialmente das mulheres negras. A autora afro-americana reconhece o caráter dúbio do trabalho intelectual e realça a necessidade de "andar em meio a esse sofrimento para trabalhar com ideias que possam servir de catalisadoras para a transformação de nossa consciência e nossas vidas, e de outras, é um processo prazeroso e extático" (HOOKS, 1995, p. 478). A autora compreende que as mulheres negras tem um ponto de vista peculiar por conta da sua múltipla marginalização e por isso são capazes de "criticar a hegemonia racista, classista e sexista dominantes e vislumbrar e criar uma contra-hegemonia" (HOOKS, 2015, p. 208).

Nessa mesma esteira compreensiva, Patricia Hill Collins (2016) assevera que as mulheres negras possuem um estatuto de outsider whithin, ou "estrangeiras de dentro", que confere a elas uma perspectiva única diante da realidade. Esse status informa uma capacidade singular e ampliada, atrelada à localização societária e pertencimento identitário das mulheres negras, de produção de análises distintas circundadas por questões como gênero, raça e classe. Em relação às intelectuais negras, a autora afirma que essa posição de outsider whithin favorece a elevação de uma capacidade de apreender padrões que dificilmente poderiam ser captados por quem foi forjado em campos hegemônicos. Essas estrangeiras de dentro podem ser compreendidas também como "intelectuais marginais" cuja postura crítica favoreceria um desenvolvimento criativo das ciências (COLLINS, 2016). 
Com base no que foi escrito até agora, podemos identificar os contornos dinâmicos e não monolíticos de um Pensamento Feminista Negro que, mais que denunciar as múltiplas opressões que acometem as mulheres negras, tem buscado evidenciar as especificidades, inclusive epistêmicas, relacionadas a esse singular pertencimento que articula pensamento abstrato e ação pragmática. Um dos temas chave que permeiam o Pensamento Feminista Negro contemporâneo é a importância da autodefinição das mulheres negras, desafiando as imagens estereotipadas consolidadas. Os estereótipos, ao controlarem e definirem imagens acerca das mulheres negras, têm cumprido um papel central na desumanização e exploração do grupo. Assim sendo,

\begin{abstract}
Feministas negras têm questionado não apenas o que tem sido dito sobre mulheres negras, mas também a credibilidade e as intenções daqueles que detêm o poder de definir. Quando mulheres negras definem a si próprias, claramente rejeitam a suposição irrefletida de que aqueles que estão em posições de se arrogarem a autoridade de descreverem e analisarem a realidade têm o direito de estarem nessas posições. Independentemente do conteúdo de fato das autodefinições de mulheres negras, o ato de insistir na autodefinição dessas mulheres valida o poder de mulheres negras enquanto sujeitos humanos. (COLLINS, 2016, p. 104).
\end{abstract}

No Brasil, são muitos os estereótipos que recaem sobre a população negra, em especial sobre as mulheres negras, e que são responsáveis pela ativação de processos de discriminação nos mais variados ambientes. Lélia Gonzalez (1982) esteve atenta aos estereótipos e advertiu em seus escritos que a história oficial contada sobre o Brasil e sobre o período colonial apresenta e fixa um imaginário coletivo de pessoas negras como passivas, infantis, incapazes intelectualmente e que aceitaram, sem se opor, a condição de escravizadas. A figura da mãe preta, por exemplo, cuja função era garantir o bom funcionamento da casa grande realizando desde as tarefas domésticas até a amamentação e criação dos filhos dos senhores, tem sido apresentada como um símbolo de integração e de harmonia racial. $\mathrm{O}$ estereótipo da mãe preta representaria "o negro acomodado, que passivamente aceitou a escravidão e a ela correspondeu segundo a maneira cristã, oferecendo a outra face ao inimigo" (GONZALEZ, 1982, p. 72). São muitos outros exemplos que demonstram como a fixação de estereótipos envolvendo as mulheres negras cumpre o perverso papel social de retirar-Ihes autonomia, capacidade de resistência e até mesmo desumanizá-las. 
Os estereótipos referentes às mulheres negras foram construídos desde o período colonial, muito embora não se restrinjam a ele. Contemporaneamente, a representação social da mulher negra ainda está limitada à figura da empregada doméstica ou da "mulata" sempre disponível sexualmente (GONZALEZ, 1982). É evidente que a "representação iconográfica da negra imprime na consciência cultural coletiva a ideia que a mulher negra está neste planeta principalmente para servir aos outros" (HOOKS, 1995, p. 468) e esse ato de servir é válido tanto para a mesa quanto para a cama. Neste sentido, a hiper-sexualização das negras a partir da figura da "mulata" converte-se em uma forma eficaz de reduzi-las a mero objeto sexual ou produto para exportação/consumo (GONZALEZ, 1982). Como exemplo do que está sendo afirmado, podemos nos ater na forma como as mulheres negras são representadas nos meios de comunicação, ainda muito associadas a uma sensualidade e erotismo extremado.

Essas representações estereotipadas dificultam uma apreensão coletiva das mulheres negras como intelectuais, ou produtoras de saberes. Herdeiras de um passado escravista que as aprisionou na condição de servir e que são atualizadas com as contemporâneas representações, não mais como mãe preta, mas como empregada doméstica etc., às negras resta uma difícil associação com intelectualidade. O pressuposto é que primeiramente aconteça a desestruturação de uma imagem coletiva estereotipada para que a posteriori seja vislumbrada uma outra imagem. Urge a quebra dos estereótipos para que os sujeitos revelem potencialidades e humanidades que os constitui. bell hooks (1995) também argumenta que essa representação estereotipada é um dos fatores impeditivos às mulheres negras de se tornarem intelectuais e há sempre uma "necessidade de demonstrar e defender a humanidade dos negros incluindo sua habilidade e capacidade de raciocinar logicamente, pensar coletivamente e escrever lucidamente" (HOOKS, 1995, p. 472).

Diante de um cenário como esse, a autodefinição, conforme proposta por Patricia Hill Collins (2016) e pelo Pensamento Feminista Negro, emerge como importante estratégia de desestruturação de estereótipos e instituição de outras perspectivas. Contemporaneamente, sobremaneira em decorrências das políticas afro-reparatórias instituídas nas universidades brasileiras, a autodefinição tem sido uma realidade possível para as negras que adentram nos espaços de poder "com seus conhecimentos, demandas políticas, valores, corporeidade, condições de vida, 
sofrimentos e vitórias" (GOMES, 2012, p. 99). A ampliação do direito à educação e a democratização do ensino superior ocorridas nos últimos anos tem aumentado a presença de sujeitos antes excluídos ou invisibilizados, que são desconsiderados como produtores e reprodutores de conhecimento. As universidades têm lentamente se constituído em ambientes mais plurais com essas presenças e com a circulação de saberes não hegemônicos, que tem favorecido a emergência de espaços mais criativos, inclusive no campo de novas epistemologias com abertura para os saberes decoloniais, e mais propositivos, no campo político que força mudanças colaboradoras para a efetivação de Direitos Humanos.

Nos últimos anos, com a adoção de políticas públicas de incentivo à democratização do acesso ao Ensino Superior houve um aumento na entrada de mulheres negras nas universidades brasileiras, embora tenham sido mantidas as desvantagens estruturais que sobre elas recaem, como demonstrado no relatório de iniciação científica de Hariel Revignet e Luciana Dias (2018). Dentre essas políticas públicas, trazemos aqui, para exemplificar, a expansão de vagas na rede federal, com a criação e ampliação de Universidades e Institutos Federais; a implementação de políticas de cotas para pessoas negras, indígenas e população de baixa renda em universidades públicas; o Programa Universidade para Todos (PROUNI), que oferece bolsas de estudos em IES privadas para estudantes egressos de escolas públicas. Essas, e outras ações, estamparam na atual configuração das universidades brasileiras presenças não hegemônicas, tais quais as de mulheres negras.

Rita Laura Segato (2006) aponta que a adoção de políticas públicas de cidadania, como as ações afirmativas, impacta não só no ambiente acadêmico como na sociedade em geral. As cotas para pessoas negras têm, segundo a antropóloga argentina, uma eficácia reparadora porque representam uma possibilidade de ressarcimento, ainda que parcial, às perdas históricas sofridas. As ações afirmativas apresentam uma dupla potência que abarca as dimensões estética e ética durante sua aplicação. Neste sentido, as ações afirmativas podem não apenas aumentar a representatividade na composição étnico-racial nos espaços institucionais onde são aplicadas, evidenciando sua dimensão mais estética, como também podem contribuir para uma publicização das práticas racistas, auxiliando na condenação destas práticas e também na adoção de ações educativas antirracistas. Esta segunda é uma perspectiva mais ética (DIAS, 2012). 
Edilza Correia Sotero (2013) demonstra um aumento nas taxas de escolarização de pessoas negras entre os anos de 2003 e 2009. A estudiosa apresenta em gráficos que a presença de mulheres negras, e homens negros, na condição de estudantes do ensino superior aumentou cinco pontos percentuais no intervalo de tempo analisado. Todavia, aponta também que mesmo com esse aumento das taxas de escolarização, a presença de mulheres brancas e homens brancos como estudantes de ensino superior nas universidades brasileiras ainda é significativamente maior que a de mulheres negras e homens negros. Se considerarmos, assim como informa o IBGE (VIEIRA, 2016), que a população nacional brasileira é composta por quase $54 \%$ de pessoas negras (pretas + pardas), o país segue com sub-representação de pessoas negras como discentes em suas universidades.

Além da sub-representação, as universidades tem sido ambientes hostis especialmente às mulheres negras. Delcele Mascarenhas Queiroz e Carlinda Moreira dos Santos (2016) analisam a inserção das mulheres negras nas universidades a partir de experiências de discentes negras da Universidade Federal da Bahia (UFBA) em cursos reconhecidos e apresentados, dentro e fora da universidade, como de elevado prestígio social, tais como Medicina, Direito, Odontologia, Engenharias, Psicologia e Comunicação/Jornalismo (QUEIROZ; SANTOS, 2016, p. 74). As autoras do estudo consideram que, para as mulheres negras, estar nesses ambientes é assumir o ônus do estrangeirismo que "implica um enorme esforço cotidiano, que exige o confronto com uma realidade que as exclui e as desqualifica, realidade que insiste em querer lhes fazer crer que esse não é o seu lugar" (QUEIROZ; SANTOS, 2016, p. 86). Esse aprendizado adquirido com o estudo das experiências da UFBA pode ser estendido para outras universidades brasileiras ainda vinculadas às perspectivas moderno-coloniais que afirmam as hegemonias e toleram as diferenças somente no campo da exceção. Érika Costa Silva (2016) estudou aprofundadamente, em uma pesquisa qualitativa abrigada no curso de Ciências Sociais e baseada em entrevistas em profundidade a estudantes negras da UFG, narrativas de estudantes negras cotistas que demonstram como as universidades ainda são territórios de reprodução de perversidades, estigmas, hostilidades e racismos contra as mulheres negras que ocupam esses lugares em busca de escolarização, aprimoramento intelectual e qualificação profissional. 


\section{Saberes decoloniais, pensamento negro e contribuições teóricas}

Ainda que tenhamos hoje ampliadas discussões sobre Direitos Humanos, não temos como desconsiderar as dificuldades enfrentadas para assegurar a realização da dignidade humana para segmentos significativos da população mundial. O que de fato tem sido pontuado, e vastamente denunciado, é que esses direitos não têm sido efetivados e, em muitas situações, não são sequer reconhecidos. Neste sentido, repensar questões de efetivação/violação de Direitos Humanos a partir de chaves compreensivas decoloniais e ligadas a um pensamento negro pode contribuir para o desenvolvimento de estratégias e alternativas, não eurocêntricas, de efetivação Direitos Humanos. Uma perspectiva decolonial permite considerar presenças e narrativas que foram histórica e politicamente silenciadas, ocultadas ou eliminadas de campos de discussão, de poder e de produção e reprodução de conhecimentos. É o que pudemos constatar na Pós-Graduação stricto sensu em Antropologia Social, da UFG, que no primeiro semestre de 2019 ofereceu a disciplina optativa "Epistemologias e Feminismos Negros" e contou com docente, discentes e autoras (bibliografia) quase que exclusivamente negras. O Dossiê Epistemologias e Feminismos Negros (2019), da Revista Humanidades \& Inovação, evidencia vozes, pensamentos e corpos dissidentes, e negros, em perspectiva decolonial, já que permite reconhecer os perversos efeitos contemporâneos da colonização (SANTOS; DIAS, 2019).

Os estudos decoloniais tem contribuído para uma análise crítica da realidade, latino-americana como um todo, que reconheça os efeitos atuais das heranças coloniais. Conforme Walter Mignolo (2007), o pensamento decolonial surgiu com a Modernidade/Colonialidade, enquanto um saber contra-hegemônico e de resistência à dominação europeia. É um pensamento que tem sido construído nas Américas nos últimos 500 anos a partir do pensamento indígena, do pensamento afro-caribenho e vem se manifestando nas lutas travadas pelos povos latino-americanos. $O$ pensamento decolonial emerge em sintonia com o conceito de "colonialidade do poder", que fora desenvolvido por Anibal Quijano (2010) e sustenta as análises decoloniais. A colonialidade do poder é um fator que, além de perpetuar as estruturas de dominação desde o período da administração colonial, atualiza essa dominação, disfarçando-a de modernidade. Estamos falando de uma estrutura complexa que 
engloba o controle da economia, dos recursos, da raça, do gênero e sexualidade, do saber e das formas de conhecimento (BALLESTRIN, 2013).

A apreensão do pensamento decolonial habilita compreender a ideia de "raça" como principal organizadora das hierarquias no sistema-mundo. A raça, construída com base no fenótipo e utilizada para caracterizar indivíduos e estabelecer hierarquias e relações de poder, foi sendo burilada histórica, social e politicamente nos últimos cinco séculos. O estabelecimento dessas relações de poder tem início nas Américas e é mundialmente imposto. Assim sendo, "a população de todo o mundo foi classificada, antes de mais, em identidades 'raciais' e dividida entre os dominantes/superiores 'europeus' e os dominados/inferiores 'não-europeus'" (QUIJANO, 2010, p. 107). No Brasil, raça apresenta um inquestionável valor sociológico, sendo que foi com a construção de uma pauta antirracista que se alterou todo um percurso de teorização do racismo. Uma definição pertinente de raça informa que estamos diante de "[...] pessoas que numa dada sociedade são socialmente definidas como diferentes de outros grupos em virtude de certas diferenças físicas reais ou putativas" (BERGUE, 1970, p. 10).

Além da ideia de raça, o par modernidade/colonialidade também é central para entender a argumentação da perspectiva decolonial. Um de seus principais postulados é que "a colonialidade é constitutiva da modernidade e não derivada" (MIGNOLO, 2005, p. 36), ou seja, não há modernidade sem a colonialidade. 0 colonialismo se diferencia da colonialidade na medida em que o primeiro está associado ao controle da autoridade política, dos recursos produzidos e da mão de obra de um determinado povo, enquanto o segundo apresenta raízes profundas que sobrevivem como uma estrutura subjetiva de dominação cultural, política, sexual e epistêmica, sustentando-a, ainda que as independências formais das colônias americanas tenham acontecido (MIGNOLO, 2005). Enrique Dussel (2005) aponta dois conceitos de modernidade: o primeiro deles, surgido a partir da Reforma Protestante, do lluminismo e da Revolução Francesa, mais amplamente difundido, diz respeito à noção de evolução, ou seja, uma emancipação ou caminho percorrido pela humanidade rumo a uma afirmação da razão; Já o segundo filia-se à tese de que a modernidade nasceu no ano de 1492 a partir do momento em que a Europa (bem como seus Estados, seus exércitos, sua filosofia etc.) se afirmou como o centro da história mundial (DUSSEL, 2005). 
Importante notar, nesta segunda perspectiva, o surgimento da modernidade com a afirmação da Europa no centro da história mundial, reservando para o restante do mundo a classificação de "periferia". Neste sentido, o sucesso do projeto modernizante depende fortemente da noção de que a civilização moderna é mais desenvolvida e superior (DUSSEL, 2005). Há também uma crença de que essa civilização moderna é responsável por promover o desenvolvimento da periferia classificada como inferior, bárbara e primitiva. E, diante de uma resistência desses povos e populações periféricos à modernização, o uso da força e da violência fica autorizada como forma de garantir a realização do projeto modernizante. Esse esquema compreensivo das estruturas de dominação colonial faz com que nos aproximemos aqui, em termos reflexivos, de questões referentes à violação de Direitos Humanos e à perda de dignidade.

$\mathrm{Na}$ medida em que a modernidade confere à Europa as condições de estabelecer direitos, ao mesmo tempo em que imputa ao resto da humanidade o mesmo patamar de desenvolvimento racional para que esta usufrua de direitos, nos deparamos com a construção dos direitos no mesmo bojo de um projeto modernizante. Podemos considerar, portanto, que os Direitos Humanos são "produto da cultura e do esforço político do Ocidente e, portanto, pouco ou nada tem a ver com a história dos povos não ocidentais" (BRAGATO, 2014, p. 218). Partindo dessa consideração, Ramón Grosfoguel (2009) informa que qualquer discussão acerca dos Direitos Humanos deve considerar três postulados principais, quais sejam:

$\left.1^{\circ}\right)$ Los Derechos Humanos a mediados del siglo XX son una continuación de los diseños Globales/Coloniales occidentales de los Derechos de Pueblos en el siglo XVI y de los Derechos del Hombre en el siglo XVIII. $2^{\circ}$ ) La noción de la 'dignidad humana' en el primer artículo de la Declaración Universal de los Derechos Humanos de las Naciones Unidas es una noción occidentalocéntrica que privilegia al individuo sobre definiciones de matriz colectiva. $3^{\circ}$ ) La retórica de los Derechos Humanos se aplicó siempre contra los enemigos del Frente Unido Imperialista Occidental y se pasó por alto cuando se trataba de regímenes dictatoriales amigos de occidente. (GROSFOGUEL, 2009, p. 158).

Ao nos atentarmos ao primeiro postulado, notamos uma retomada dos debates sobre a extensão dos direitos ao longo dos séculos. Os Direitos das Pessoas no século XVI se referem às discussões entre membros da elite eclesiástica da Espanha para definir o que seria feito com os povos encontrados nas Américas, sem considerar 
sua autonomia e autodeterminação. Nesse contexto, o objetivo do julgamento de Valladolid em 1552 foi definir sobre a humanidade ou não dos "índios". Os argumentos ao longo do julgamento pautavam de um lado que "os índios eram seres sem alma e, portanto, animais que poderiam ser escravizados no processo do trabalho" ou, de outro lado, que "os índios possuíam uma alma, em estado bárbaro, necessitando de cristianização" (GROSFOGUEL, 2016, p. 38).

Já os Direitos do Homem elaborados no contexto lluminista continuaram ancorados na lógica eurocêntrica e patriarcal, restringindo esses direitos apenas aos homens brancos, cristãos, heterossexuais e ocidentes. Na atualidade, conceitos como humanidade e dignidade humana são heranças diretas desses debates ocidentalizados, seculares e pautados na tradição ocidental da exclusão, subordinação e inferiorização das epistemologias não ocidentais. Diante desse cenário histórico, a defesa que se faz é por uma concepção multicultural e pluriepistêmica de Direitos Humanos, que somente é possível a partir do alargamento do conceito de "humano" que deve romper com, e ir além de, uma noção patriarcal racista e eurocêntrica (GROSFOGUEL, 2009).

Fernanda Frizzo Bragato (2014) se baseia nas contribuições decoloniais para problematizar os fundamentos e a construção do discurso dominante dos Direitos Humanos. Para ela, a dignidade humana pautada na racionalidade não tem implicado no reconhecimento de que todas as pessoas são iguais ou possuam um mesmo valor, mas sim que há, entre homens e mulheres, diferenças e hierarquias. Um discurso construído gradativamente ao longo dos séculos determinou a inferioridade de pessoas negras, indígenas, mulheres, homossexuais etc. Esse mesmo discurso de poder permitiu a hierarquização da humanidade e influenciou as construções sociais vigentes e ordenadoras das interações socioculturais. Contemporaneamente, são os sujeitos que não foram considerados seres humanos integrais ou que foram desumanizados por essa poderosa e perversa hegemonia, aqueles que mais necessitam de reconhecimento e efetivação dos Direitos Humanos. A partir de outro locus de enunciação, Frantz Fanon (2008, p. 26) refina um conceito de humanidade ao enfatizar que "o negro não é um homem" e assevera que "De um homem exige-se uma conduta de homem; de mim, uma conduta de homem negro" (2008, p. 107), qual seja, "confinado", "encolhido", “com pulsões imorais" e "não civilizado" (2008, p. 161). Ou seja, são matérias diferentes "o homem", humano para o qual os Direitos Humanos 
são efetivados e o "homem negro" desumanizado para o qual os Direitos Humanos são violados.

No contexto brasileiro, a partir do que podemos chamar de um pensamento negro, processos de efetivação/violação de Direitos Humanos estão atrelados a construções históricas e ideológicas nas quais o racismo estrutura questões de classe e de gênero. O desafio de pensar as mulheres negras como sujeitos que evidenciam essa afirmação exige de nós, assim como exigiu de Thula Pires (2016), a retomada da concepção de "amefricanidade" (GONZALEZ, 1988) como uma necessidade para a restituição de dignidades perdidas em decorrência de preconceitos e discriminações múltiplas. A Amefricanidade, como uma categoria político-cultural, tem o potencial de captar a experiência das pessoas negras, ou afrodescendentes, nas Américas e incorporar "um processo histórico de intensa dinâmica cultural (adaptação, resistência, reinterpretação e criação de novas formas) que é afrocentrada" (GONZALEZ, 1988, p. 76). Ao centrar a análise na experiência das pessoas negras, ou afrodescendentes, no continente americano, em especial na América Latina e no Caribe, Lélia Gonzalez, ao mesmo tempo em que colabora para delinear um Pensamento Feminista Negro, propõe uma ruptura epistemológica e política com as heranças coloniais e imperialistas. Essa ruptura tem um potencial transformador das relações hierarquizadas e indica uma perspectiva decolonial que reconhece outros saberes, linguagens, práticas e direitos gestados de maneira autônoma e autodeterminante.

Para pensar questões de efetivação/violação de Direitos Humanos no Brasil e na América Latina há que se considerar a "articulação das categorias de raça, classe, sexo e poder" (GONZALEZ, 1988, p. 138). Esta antropóloga negra brasileira salienta que "a afirmação de que somos todos iguais perante a lei assume um caráter nitidamente formalista em nossas sociedades" (GONZALEZ,1988, p. 138), isso porque "o racismo latino-americano é suficientemente sofisticado para manter negros e indígenas na condição de segmentos subordinados no interior das classes mais exploradas, graças a sua forma ideológica mais eficaz: a ideologia do branqueamento" (GONZALEZ, 1988, p. 138). Em diálogo estreito com Lélia Gonzalez, Abdias do Nascimento (1980), inspirado nas experiências de resistências de africanos escravizados e seus descendentes no esforço de garantir a sua liberdade e dignidade desde o século $\mathrm{XV}$, apresenta o conceito de quilombismo. Para o autor, "a sociedade 553 
brasileira contemporânea pode se beneficiar com o projeto do quilombismo, uma alternativa nacional que se oferece em substituição ao sistema desumano do capitalismo" (NASCIMENTO, 1980, p. 9). Sua proposta de um Estado Nacional Quilombista, inspirada na experiência da República dos Palmares do século XV, se baseia em uma sociedade livre, justa, igualitária e soberana, na qual "o igualitarismo democrático quilombista é compreendido no tocante a sexo, sociedade, religião, política, justiça, educação, cultura, condição racial, situação econômica, enfim, todas as expressões da vida em sociedade" (NASCIMENTO, 1980, p. 10).

A amefricanidade e o quilombismo tomados aqui como decorrentes de um pensamento negro apresentam uma relação direta com o pensamento decolonial, ainda que não tenham sido forjados pressupondo essa relação. Essas duas categorias do pensamento negro "são algumas possibilidades para novas gramáticas de Direitos Humanos, 'em versões internas' brasileiras, a partir das experiências afros, pelo viés da crítica à colonialidade do poder, saber e ser, um verdadeiro exercício de afrografias e pedagogias da diferença." (BALDI, 2015, p. 64). O pensamento que vai se fazendo presente a partir dessas reflexões é marcado pela criticidade e por uma proposta de episteme protagonizada por sujeitos que foram histórica e politicamente subalternizados e violentamente - já que inferiorizados, excluídos, silenciados, explorados e marginalizados - alocados em projeto eurocêntrico da modernidade. Essas "epistemologias de fronteira" (GROSFOGUEL, 2008, p. 140) revelam saberes decoloniais tais quais aqueles que são enunciados pelas mulheres negras intelectuais que ocupam hoje, ainda que de maneira insuficiente em termos quantitativos, as universidades brasileiras, legítimas produtoras de conhecimentos.

As universidades brasileiras, a partir da adoção de ações afirmativas e políticas públicas afro-reparatórias, têm contado com presenças de mulheres negras, mas não somente, que além de reivindicarem processos de restituição de dignidades perdidas e de efetivação de direitos violados, têm colaborado para a redefinição de noções e teorias, até então hegemonicamente cristalizadas, como saberes, cidadania, democracia, igualdade, racismo, machismo e tantas outras. Esses sujeitos, com suas propostas de epistemologias de fronteira, apresentam para a modernidade/colonialidade possibilidades transformadoras de relações que foram instituídas de maneira opressora e unilateral a segmentos subalternizados. Mais que destacar a pluralidade de saberes e informar outras racionalidades possíveis, as 
presenças de negras intelectuais nas universidades têm contribuído para que o Estado seja agente em processos de efetivação de Direitos Humanos, tais como o direito à educação, dentre tantos outros. Finalmente, há que se considerar que a Educação em/para Direitos Humanos, que sustenta inclusive o direito à educação, pode ser tomada como fundação para transformações sociais. O antirracismo, o feminismo e as lutas contra-hegemônicas, além de comporem a pauta de um feminismo negro presente nas universidades hoje, dialogam francamente com propostas de uma Educação em/para Direitos Humanos.

\section{Considerações Finais}

Processos em torno da produção de conhecimentos nas universidades brasileiras foram aqui pensados a partir de uma afirmação de sua construção histórica no bojo da modernidade colonial. O exercício de identificar a composição racial e de gênero das universidades é importante para que sejam problematizados esses processos de produção de conhecimentos que são também resultantes de uma hierarquização de sujeitos. Uma consideração importante é a de que os conhecimentos que transitam pelas universidades ainda são majoritariamente fundamentados em epistemicídios e na universalização da contribuição europeia, ou anglo-saxã, ou ocidental, de forma que toda uma produção intelectual de sujeitos pensantes do sul global continua sendo desconsiderada.

A adoção de ações afirmativas, ou políticas afro-reparatórias, nas universidades brasileiras nos últimos anos têm alterado as discussões acerca da questão racial, étnica e de gênero, ao mesmo tempo em que têm inserido outras epistemologias questionadoras do status quo. No ambiente das universidades, pode ser observado um aumento, ou uma revelação, de reações hostis à presença de discentes negros e negras, evidenciando a permanência do racismo na sociedade brasileira. Contemporaneamente, em decorrência dessas presenças plurais, há também uma demanda pela tematização de antirracismos e feminismos no âmbito das disciplinas e das interações nesses ambientes de produção de conhecimentos, nos moldes da disciplina "Epistemologias e Feminismos Negros", ofertada pelo Programa de Pós-Graduação em Antropologia Social da UFG. Há também uma demanda pela revisão de um passado histórico colonial visto por outras lentes e pelo 
reconhecimento de autorias até então negligenciadas na academia, com a inserção de outras narrativas e até mesmo de outras linguagens.

Um olhar mais detido nas múltiplas presenças nas universidades brasileiras contemporaneamente e à luz do Pensamento Feminista Negro possibilitou perceber um aumento das presenças das mulheres negras, ainda quantitativamente tímidas, mas já buscando uma afirmação de seu lugar enquanto intelectuais que se apresentam para a interlocução acerca de teorias, métodos, vivências e "escrevivências" (EVARISTO, 2006). Entendemos que o potencial criativo e cognitivo do status outsider whithin, que é ocupado pelas intelectuais negras brasileiras nas universidades, contribui para o reconhecimento de uma pluralidade de saberes que subverte as representações estereotipadas, que vigoram como imaginário coletivo constituído e constituidor das mulheres negras.

Conforme foi destacado neste manuscrito, uma das principais características do Pensamento Feminista Negro é a apreensão da questão racial interseccionada com questões de sexo/gênero, de classe e de sexualidade. À guisa de conclusão, enfatizamos que em contextos multirraciais, raça é um componente essencial para compreender e explicar violências e violações de direitos sofridas por mulheres negras, bem como pelos diferentes raciais desses contextos. A interseccionalidade, nascida no seio do Pensamento Feminista Negro, eleva-se, nesse sentido, como uma perspectiva metodológica essencial para as reflexões relacionadas à temática dos Direitos Humanos. A perspectiva da interseccionalidade adquire também centralidade no combate a um universalismo retórico, que encobre desigualdades estruturais.

A abertura para a circulação de uma pluralidade de saberes permite revelar os saberes decoloniais e sua potencialidade para efetivação de Direitos Humanos. Todo um pensamento decolonial se faz notar por meio do reconhecimento das heranças coloniais nas estruturas de dominação; da centralidade da raça/etnia, do sexo/gênero e da classe como principais fatores que organizam as hierarquias no sistema-mundo; da reinterpretação da noção de modernidade, evidenciando a colonialidade como constitutiva dessa modernidade; e, da ampliação de narrativas, pertencimentos e trajetórias socioculturais e históricas para além do legado europeu ou ocidental hegemônico.

O conceito de humanidade que fora elaborado a partir da noção europeia de racionalidade e a raça como principal organizadora das hierarquias no sistema-mundo 
fizeram com que alguns sujeitos fossem considerados mais humanos do que outros. Para aqueles considerados humanos na sua totalidade, garantido está o acesso aos direitos, às políticas públicas, aos recursos materiais e, também, o reconhecimento das suas identidades, subjetividades, racionalidades e intelectualidades. Já para aqueles que foram alocados abaixo da linha da humanidade, resta uma árdua luta em vários campos e, protagonizada por eles mesmos, para a conquista de direitos, políticas públicas, acesso a recursos, afirmação de identidades e subjetividades e asseveração de racionalidades e intelectualidades.

Nessa luta por reconhecimento de direitos e combate às desigualdades sistêmicas e estruturais que foram herdadas da modernidade colonial, as noções de amefricanidade, de Lélia Gonzalez, e de quilombismo, de Abdias do Nascimento, são tomadas como alternativas para a compreensão dos Direitos Humanos, já que essas categorias permitem reconhecer a centralidade das hierarquias raciais na manutenção das desigualdades. É nesse contexto que o Pensamento Feminista Negro ocupa a cena nas universidades brasileiras, em decorrência das, ainda poucas, presenças das intelectuais negras, como uma teoria/ação que possibilita compreender, qualificandoa, a complexidade da defesa e da afirmação dos Direitos Humanos, tão urgentes na atualidade.

\section{Referências Bibliográficas}

ANDIFES, Associação Nacional dos Dirigentes das Instituições Federais de Ensino Superior. Políticas de expansão e inclusão mudam o perfil dos estudantes. 2016. Disponível em: <https://www.ufg.br/n/90869-politicas-de-expansao-e-inclusaomudam-o-perfil-de-estudantes>. Acessado em 17 de agosto de 2019.

BALDI, César. Para uma sociologia das ausências da descolonização dos direitos humanos: notas iniciais sobre os aportes afros. Hendu, v. 6, n. 1, p. 47-68, 2015. Disponível em: <http://www.periodicos.ufpa.br/index.php/hendu/article/view/2461>.

BALLESTRIN, Luciana. América latina e o giro decolonial. Revista Brasileira de Ciência Política, v. 11, p. 89-117, 2013.

BERGHE, Pierre van den. Race and Ethnicity. New York: Basics Books Inc., 1970.

BRAGATO, Fernanda Frizzo. Para além do discurso eurocêntrico dos Direitos Humanos: contribuições da descolonialidade. Revista Novos Estudos Jurídicos Eletrônica, vol. 19 - n. 1, p. 201-230, jan-abr 2014. 
CARDIM, Nathália; CARAMORI, lana. UnB: número de estudantes negros triplica em 10 anos. Metrópoles. 2019. Disponível em: <https://www.metropoles.com/distritofederal/educacao-df/unb-numero-de-estudantes-negros-triplica-em-10-anos >.

Acessado em 10 de dezembro de 2019.

CARNEIRO, Aparecida Suelaine. Mulheres e educação: gênero, raça e identidades. Dissertação de Mestrado em Educação, Universidade Federal de São Carlos, Sorocaba, 2015.

CARNEIRO, Aparecida Sueli. A construção do outro como não-ser como fundamento do ser. Tese de doutorado em Educação, Universidade de São Paulo - USP, 2005.

CASTRO-GOMEZ, Santiago; GROSFOGUEL, Ramón (Ed.). El giro decolonial: reflexiones para una diversidad epistémica más allá del capitalismo global. Bogotá: Siglo del Hombre Editores; Universidad Central, Instituto de Estudios Sociales Contemporáneos y Pontificia Universidad Javeriana, Instituto Pensar, 2007.

COLLINS, Patricia Hill. Aprendendo com a outsider whithin: a significação sociológica do pensamento feminista negro. Revista Sociedade e Estado, Volume 31, n. 1, 2016.

DIAS, Luciana de Oliveira. Tema contextual como possibilidade transdisciplinar na educação intercultural. Escritas: Revista de História de Araguaína, v. 12, n 1, p. 3448, 2020.

DIAS, Luciana de Oliveira. Desigualdades Étnico-raciais e Políticas Públicas no Brasil. Revista da ABPN, v. 3, n 7, p. 07-28, 2012.

DUSSEL, Enrique. "Europa, modernidade e eurocentrismo". In: LANDER, Edgardo (Org. ). A colonialidade do saber: eurocentrismo e ciências sociais. Perspectivas latinoamericanas. Buenos Aires: Colección Sur Sur, CLACSO, 2005.

EVARISTO, Conceição. Becos da memória. Belo Horizonte: Mazza Edições, 2006.

FANON, Frantz. Pele negra, máscaras brancas. Tradução de Renato da Silveira. Salvador: EDUFBA, 2008.

FERREIRA, Lola. Menos de 3\% entre docentes da pós-graduação, doutoras negras desafiam racismo na academia. Gênero e Número. 2018. Disponível em: http://www.generonumero.media/menos-de-3-entre-docentes-doutoras-negrasdesafiam-racismo-na-academia/ Acessado em 10 de dezembro de 2019.

FIGUEIREDO, Ângela; GROSFOGUEL, Ramón. Racismo à brasileira ou racismo sem racistas: colonialidade do poder e a negação do racismo no espaço universitário. Sociedade e Cultura, Goiânia, v. 12, n. 2, p. 223-234, 2009.

GOMES, Nilma Lino. "Intelectuais negros e produção do conhecimento: algumas reflexões sobre a realidade brasileira". In: SANTOS, Boaventura de Souza; MENESES, Maria Paula (Orgs.). Epistemologias do Sul, São Paulo: Cortez, 2010. 
GOMES, Nilma Lino. Relações Étnico-Raciais, Educação e Descolonização dos Currículos. Currículo sem Fronteiras, v. 12, p. 98-109, 2012.

GONZALEZ, Lélia. A categoria político-cultural da amefricanidade. In: Tempo Brasileiro. n. 92-93, Rio de Janeiro: Ed. Global, jan./jun. 1988.

GONZALEZ, Lélia. "A Mulher Negra na Sociedade Brasileira (Uma abordagem político-econômica)". In: MADEL, Luz. (org.). O lugar da Mulher (Estudos sobre a condição feminina na sociedade atual). Rio de Janeiro: Graal, 1982.

GONZALEZ, Lélia. Primavera para as rosas negras: Lélia Gonzalez em primeira pessoa. Diáspora Africana: Editora Filhos da África, 2018.

GRISOLIO, Lilian Marta; DIAS, Luciana de Oliveira. "Por uma educação intercultural, antirracista e democrática: as Leis 10.639/03 e 11.645/08 como marco nas políticas públicas educacionais no Brasil". In: GRIOSOLIO, Lilian Marta; DIAS, Luciana de Oliveira. (Orgs). Interfaces de Gênero I: Cultura, Educação e Étnico-racialidades. Goiânia: Gráfica da UFG, 2017.

GROSFOGUEL, Ramón. A estrutura do conhecimento nas universidades ocidentalizadas: racismo/sexismo epistêmico e os quatro genocídios do longo do século XVI. Revista Sociedade e Estado, v. 31, n. 1, 2016.

GROSFOGUEL, Ramón. Los derechos humanos y el anti semitismo después de Gaza. univ. humanist., Bogotá, n. 68, p. 157-177, July 2009.

GROSFOGUEL, Ramón. Para descolonizar os estudos de economia política e os estudos pós-coloniais: Transmodernidade, pensamento de fronteira e colonialidade global. Revista Crítica de Ciências Sociais, v. 80, p. 115-147, 2008.

hooks, bell. Mulheres negras: moldando a teoria feminista. Revista Brasileira de Ciência Política, no 16, Brasília, p. 193-210. janeiro-abril de 2015.

hooks, bell. Ensinando a transgredir: a educação como pratica da liberdade. São Paulo: Editora Martins Fontes, 2013.

hooks, bell. Intelectuais Negras. Revista Estudos Feministas, v.1, n.2, 1995.

MASO, Tchella Fernandes; YATIM, Leila. A (De)Colonialidade do Saber: uma análise a partir da Universidade da Integração Latino-americana (UNILA). Pandéia, Belo Horizonte, Fumec, Ano 11, n. 16, p. 31-53, 2014.

MIGNOLO, Walter. "El pensamiento decolonial: desprendimiento y apertura. Un manifiesto". In: CASTRO-GOMEZ, Santiago; GROSFOGUEL, Ramón (Ed). El giro decolonial: reflexiones para una diversidad epistémica más allá del capitalismo global. Bogotá: Siglo del Hombre Editores; Universidad Central, Instituto de Estudios Sociales Contemporáneos, Pontificia Universidad Javeriana, Instituto Pensar, 2007. 
, Walter. A colonialidade de cabo a rabo: o hemisfério ocidental no horizonte conceitual da modernidade. In: LANDER, Edgardo (org). A colonialidade do saber: eurocentrismo e ciências sociais. Perspectivas latinoamericanas. Ciudad Autónoma de Buenos Aires, Argentina: Colección Sur Sur, CLACSO, 2005.

NASCIMENTO, Abdias. "Documento $\mathrm{n}^{\circ}$ 7: Quilombismo: um conceito científico emergente do processo histórico-cultural das massas afro-brasileiras". In: NASCIMENTO, Abdias. Quilombismo: documentos de uma militância Pan Africana. Petrópolis: Vozes, 1980.

OLIVEIRA, Luiz Fernandes de; CANDAU, Vera Maria Ferrão. Pedagogia decolonial e educação antirracista e intercultural no Brasil. Educação em Revista, Belo Horizonte, v. 26, n. 1, p. 15-40, 2010.

QUEIROZ, Delcele Mascarenhas; SANTOS, Carlinda Moreira dos. As mulheres negras brasileiras e o acesso à educação superior. Revista da FAEEBA - Educação e Contemporaneidade, Salvador, v. 25, n. 45, p. 71-87, jan./abr. 2016.

PIRES, Thula. "Por uma concepção Amefricana de direitos humanos". In: BRANDÃO, Clarissa; BELLO, Enzo. (Org.). Direitos Humanos e Cidadania no Constitucionalismo Latino-Americano. Rio de Janeiro: Lumen Juris, 2016.

QUIJANO, Anibal. "Colonialidade do poder e classificação social". In: SOUSA SANTOS, Boaventura de; MENESES, Maria Paula (Org.). Epistemologias do Sul. São Paulo: Cortez, 2010.

REVIGNET, Hariel C. Oliveira; DIAS, Luciana de Oliveira. Equidade de Gênero no Ingresso por Cotas Raciais na Graduação da Universidade Federal de Goiás. Anais $15^{\circ}$ Conpeex: Ciência para a redução das desigualdades. ISSN: 2447-8695. 2018. Disponível em: <https://eventos.ufg.br/SIEC/portalproec/sites/site12721/2018/PIBIC.pdf>. Acessado em 20 de janeiro de 2019.

SANTOS, Débora Sirno; DIAS, Luciana de Oliveira. Saberes e pertencimentos espelhados: quando uma professora negra fala sobre feminismo negro. Revista Humanidades \& Inovação, Edição Especial: Epistemologias e Feminismos negros, v. 6, n. 16, p. 13-22, 2019.

SEGATO, Rita Laura. Cotas: por que reagimos. Revista USP, São Paulo - SP, v. 1, n. 68, p. 76-87, 2006.

SILVA, Érika Costa. Negra sou! Políticas de ações afirmativas e trajetórias de identidades de mulheres negras na UFG. Trabalho de Final de Curso de Graduação em Ciências Sociais, Universidade Federal de Goiás, 2016.

SOARES, Lissandra Vieira \& MACHADO, Paula Sandrine. "Escrevivências" como ferramenta metodológica na produção de conhecimento em Psicologia Social. Psicologia Política, v. 17, n. 39, p. 203-219, 2017. 
SOTERO, Edilza Correia. Transformações no acesso ao ensino superior: algumas implicações para os diferentes grupos de cor e sexo. In: MARCONDES, Mariana Mazzini et al (Org.). Dossiê mulheres negras: retrato das condições de vida das mulheres negras no Brasil. Brasília: Ipea, 2013.

VIEIRA, Isabela. IBGE: negros são $17 \%$ dos mais ricos e três quartos da população mais pobre. Agência Brasil. 2016. Disponível em: https://agenciabrasil.ebc.com.br/geral/noticia/2016-12/ibge-negros-sao-17-dos-maisricos-e-tres-quartos-da-populacao-mais-pobre Acessado em 20 de janeiro de 2019.

Recebido em: 28/08/2019

Aprovado em: 22/06/2020 